\title{
Utilização do músculo sóleo para perdas musculocutâneas de terço médio da perna
}

\author{
The use of soleus muscle flap in musculocutaneus losses of the middle third of \\ lower leg
}

TheOdoria HorstT

BACELAR $^{1}$

Trabalho realizado no Hospital de Pronto Socorro João XXIII e no Hospital São José, Belo Horizonte, MG, Brasil.

Artigo submetido pelo SGP (Sistema de Gestão de Publicações) da RBCP.

Artigo recebido: $17 / 3 / 2011$ Artigo aceito: 30/4/2011

\begin{abstract}
RESUMO
Introdução: Áreas lesionadas de membros inferiores são portas abertas à infecção, às perdas de plasma, sangue, eletrólitos e líquidos, além de serem responsáveis por dor intensa. Por isso, é necessário cobri-las o mais rapidamente possível, para que o paciente se estabilize precocemente, prevenindo complicações e futuras sequelas. Os retalhos musculares e musculocutâneos são opções de reparo cirúrgico destas áreas. Ao longo dos anos, sugeriram vários tratamentos com retalhos para reparações de lesões, dentre eles o retalho do músculo sóleo, foco deste trabalho. Objetivo: Relatar a experiência do autor empregando a rotação do músculo sóleo. Método: Foram tratados cirurgicamente 18 pacientes com perda de substância no terço medial da perna, utilizando a rotação do músculo sóleo, no período de 2008 a 2010. Resultados: Os resultados obtidos foram satisfatórios e sem complicações maiores. Conclusão: Este procedimento é um recurso para o tratamento de lesões decorrentes de diferentes etiologias, como úlceras, osteomielite, perda de substância cutânea de terço médio da perna e cobertura cutânea em lesões com exposição de estruturas osteotendinosas, tornando-se uma ferramenta de grande auxílio ao cirurgião plástico.
\end{abstract}

Descritores: Músculo Esquelético. Extremidade Inferior. Retalhos Cirúrgicos. Procedimentos cirúrgicos reconstrutivos.

\begin{abstract}
Introduction: Lower limb damaged areas are open doors to infection, to the loss of plasma, blood, electrolytes and fluids, in addition to being responsible for intense pain. Therefore it is necessary to cover them as soon as possible so that the patient can be stabilized preventing early complications and future sequels. Muscle and musculocutaneous flaps are used to repair these areas. Over the years several treatments with flaps have been suggested for injuries repairment, among them the soleus muscle flap, the focus of this work. Objective: To describe the author's experience using the rotation of the soleus muscle. Methods: Eighteen patients with loss of substance of the medial third of the leg were treated by using the rotation of the soleus muscle, from 2008 to 2010. Results: The results were satisfactory and without major complications. Conclusion: This is an option to treat lesions caused by various etiologies such as ulcers, osteomyelitis, loss of cutaneous substance of third middle leg, and to cover skin lesions with exposure of osteotendinous structures, becoming a great assistance tool to the plastic surgeon.
\end{abstract}

Keywords: Muscle, Skeletal. Lower Extremity. Surgical Flaps. Reconstructive Surgical Procedures.

1. Cirurgiã plástica, Membro titular da Sociedade Brasileira de Cirurgia Plástica, Belo Horizonte, MG, Brasil. 


\section{INTRODUÇÃO}

As lesões de membros inferiores com perdas de substâncias, geralmente acompanhadas de fraturas ósseas, são acontecimentos comuns em serviços de urgências médicas. Existem diversas situações que geram estresse, tanto para o médico quanto para o paciente, vários fatores de complicação, além da dor, que podem levar à amputação do membro e até à morte deste paciente.

A seleção apropriada de um retalho para reconstruir uma determinada lesão deve considerar vários fatores, como o déficit tecidual existente, as condições da zona receptora, a segurança circulatória, as alterações resultantes na zona doadora, as condições gerais do paciente e a simplicidade de sua execução.

As lesões das pernas acometem principalmente o terço médio, seguido do terço inferior e superior. A maioria das lesões de membros inferiores com perda de substância não possui exposição óssea, cerca de $80 \%$ dos casos são reparados com simples enxerto de pele ${ }^{1,2}$.

Entretanto, as lesões com perda de substância e exposição óssea, normalmente associadas a fraturas, representam um problema complicado, com solução complexa, necessitando da atuação de equipe multidisciplinar.

O prognóstico nas lesões expostas é determinado principalmente pela quantidade de tecidos desvitalizados e pelo nível e tipo de contaminação bacteriana ${ }^{3,4}$. No planejamento da cobertura das perdas de substâncias do membro inferior com exposição óssea, divide-se a perna em terços: proximal, médio e distal ${ }^{5-7}$.

Foram descritos e propostos diversos métodos para tratar as lesões de membros inferiores, como retalhos de rotação cutânea e/ou muscular, retalhos livres com técnicas de anastomoses vasculares microcirúrgicas e retalhos pediculados à distância, entre outros, cada um com suas vantagens e desvantagens ${ }^{7,8}$.

Entretanto, as perdas de substância localizadas nos membros inferiores mostram-se bastante desafiadoras quanto a sua reconstrução. Dentre todas as técnicas, os retalhos livres microcirúrgicos eram a primeira escolha quando se necessitava de uma cobertura mais elaborada. Com a publicação de McCraw et al. ${ }^{9}$, abriu-se uma nova possibilidade de tratamento dessas lesões.

Os retalhos musculares e musculocutâneos foram muito estudados nas últimas décadas. A transposição de músculos para preencher uma cavidade osteomielítica no membro inferior foi descrita pela primeira vez, em 1894, por Marius Af Schulten ${ }^{10}$. Em 1984, Cormack \& Lamberty ${ }^{11}$ descreveram as bases anatômicas desses retalhos e Gumener et al. ${ }^{12}$, em 1986, transformaram este retalho em fasciosubcutâneo, acrescentando o beneficio estético, pois a área doadora apresentava pequena sequela cicatricial.

Matheus, em 1982, e Russel, em 1988, realizaram estudos experimentais, concluindo que o músculo transposto para ferimentos contaminados apresentava capacidade de aumentar a concentração local de antibiótico ${ }^{10,13}$.

Enxertos cutâneos são contraindicados nas perdas musculocutâneas com exposição óssea. Retalhos musculares, como solear e gastrocnêmico, são opções de tratamento nesses casos e considerados primeira escolha ${ }^{14}$.

Os retalhos musculares e musculocutâneos oferecem uma atividade biológica positiva sobre tecidos atrofiados ou fibrosados, incrementando a circulação, permitindo o aporte de substâncias antibióticas, acelerando a resolução do processo infeccioso crônico e a consequente cicatrização $o^{2,15,16}$.

Em relação a estas propriedades, os retalhos musculares são superiores aos fasciocutâneos. Eles tomam destaque nas reparações de lesões, como úlcera pré-tibial crônica, fratura não consolidada com perda de substância extensa, osteomielite crônica de terço médio da perna, perda de substância cutânea em terço médio da perna, $\operatorname{etc}^{15}$.

Portanto, no terço médio, deve-se usar rotineiramente os retalhos musculares parciais. Nas coberturas extensas, a escolha recai sobre o músculo sóleo para complementar o tratamento que tem excelente arco de rotação ${ }^{17}$.

O músculo solear é um músculo grande, largo e chato, com origem na parte superior da fíbula, septo intermuscular e na linha do músculo sóleo da tíbia, com extensão variável da borda medial da tíbia. Está recoberto pelo músculo gastrocnêmio $^{16,18,19}$. Seu tendão se funde com as lâminas tendinosas do músculo gastrocnêmio para formar o tendão do calcanhar (tríceps sural) $)^{1,15,16,18,19}$ (Figura 1). É responsável pela flexão plantar do pé, atuando na marcha, no salto e na flexão da perna ${ }^{13}$.

O suprimento sanguíneo desse músculo é realizado por meio das artérias tibial posterior e fibular (classificação Tipo II de Mathes e Nahai ${ }^{20}$ ). A porção de origem tibial possui um pedículo proximal dominante e um pedículo distal secundário, ramos da artéria tibial posterior. A porção de origem

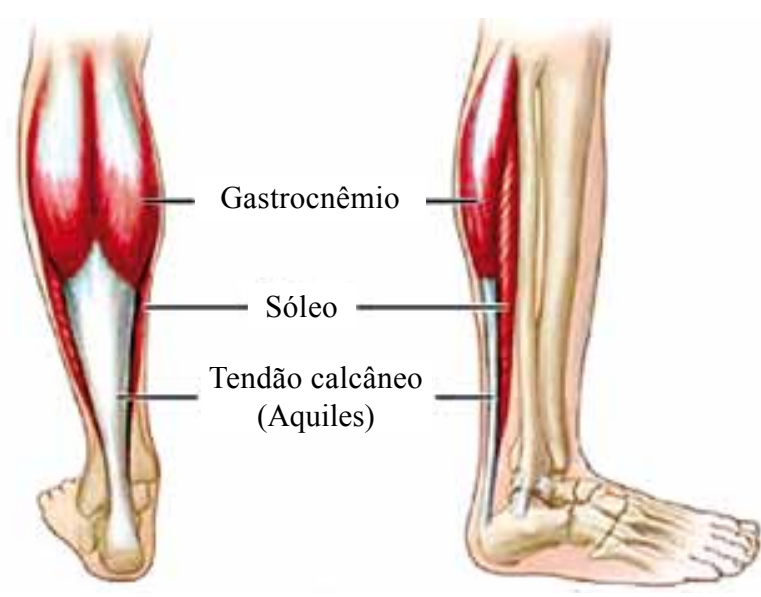

Figura 1 - Músculo sóleo. 


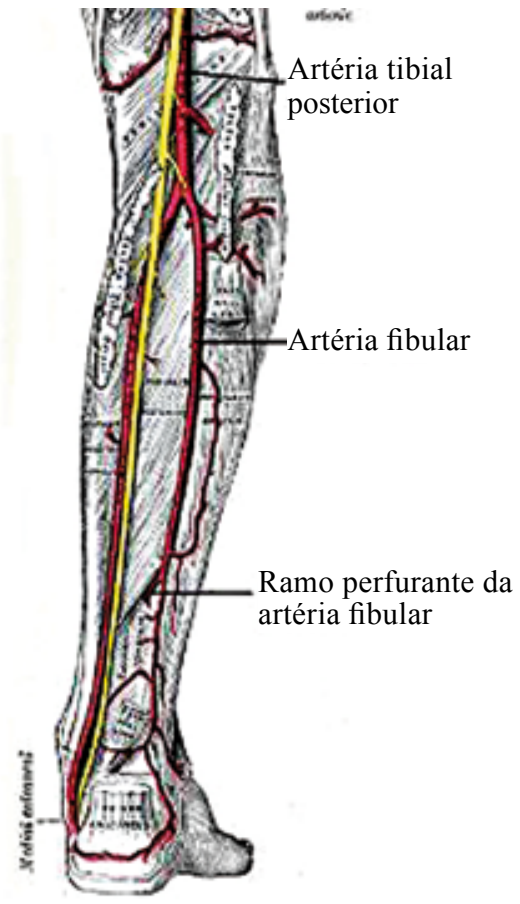

Figura 2 -Artéria tibial posterior e fibular.

fibular possui um pedículo proximal dominante, oriundo da artéria fibular ${ }^{13,16,19,21}$ (Figura 2).

O retalho solear apresenta como características versatilidade, fácil e rápida execução, amplo arco de rotação que varia de $90^{\circ}-180^{\circ}$, vascularização constante, morbidade da zona doadora bastante aceitável, padrão axial baseado no fluxo arterial invertido da artéria tibial posterior e fibular e dos ramos proximal e distal, o que o credencia como uma boa escolha para as reconstruções ${ }^{22}$.

Em relação à segurança circulatória, deve-se selecionar o retalho que apresente a maior viabilidade, considerando-se o comprimento, o volume e o arco de rotação necessários para alcançar, preencher e corrigir a deformidade ${ }^{2,15,16,20,23}$.

Os músculos sóleo são fartamente irrigados por ramos provenientes das artérias segmentares, axiais ou anastomóticas, as quais são acompanhadas por veias de calibre proporcional. A área cutânea que se sobrepõe ao músculo sóleo é irrigada por artérias miocutâneas procedentes das artérias perfurantes musculares ${ }^{13,16,20,23}$.

Ao utilizar um retalho muscular, tem-se obrigatoriamente a perda de função do referido músculo. Esta perda é substituída parcialmente por músculos adjacentes ${ }^{13,20,23}$.

As sequelas estéticas, sociais, psíquicas e funcionais, que podem se originar a partir da rotação de um retalho, devem ser insignificantes ou nulas, para impedir, provavelmente, que sobressaiam em efeito à lesão que se esta procurando reparar' ${ }^{16,20}$.

As alterações estéticas ao se utilizar o retalho muscular incluem, além da cicatriz, as assimetrias e os abaulamentos ou depressões ${ }^{20,23}$.
O retalho do músculo sóleo representa uma técnica fácil e de grande versatilidade, proporcionando melhora da circulação local e revestimento apropriado, favorecendo a osteogênese e auxilia no combate à infecção. Este trabalho foi proposto por Mc Craw et al. ${ }^{9,24}$.

Este trabalho de Mc Craw et al. foi utilizado com sucesso pordiversosautores, comoFeldmanetal. ${ }^{25}$, Morain ${ }^{26}$, Andrews et al. ${ }^{27}$, Jackson \& Scheker ${ }^{28}$, Leal et al. ${ }^{29}$ e Ramos $^{14,30}$.

O objetivo deste trabalho é relatar a experiência da autora com a utilização do retalho muscular do sóleo, como alternativa para cobertura da face ântero-medial do terço médio da tíbia, apresentando uma análise crítica da técnica em questão, dos resultados cirúrgicos obtidos e dos dados da literatura.

\section{MÉTODO}

\section{Pacientes e pré-operatório}

No período de dezembro de 2008 a fevereiro de 2010 , foram selecionados 18 pacientes atendidos em pronto socorro, com lesões com perda de substância cutânea no terço médio da perna de etiologias traumáticas diversas.

Foram avaliados $17(94,5 \%)$ pacientes do sexo masculino e $1(5,5 \%)$ do sexo feminino. O período de seguimento variou de 7 dias a 6 meses. As lesões localizavam-se no terço medial da perna em 18 pacientes.

A idade dos pacientes variou entre 23 e 58 anos, de acordo a seguinte distribuição: $9(50 \%)$ pacientes de 23 a 30 anos; $5(27,8 \%)$ pacientes de 31 a 40 anos; $3(16,7 \%)$ pacientes de 41 a 50 anos; $1(5,5 \%)$ paciente acima de 51 anos.

Foram 12 acidentes motociclísticos, 5 atropelamentos e 1 úlcera crônica por osteomielite.

Como cuidados pré-operatórios, o procedimento requer a realização de exames bioquímicos de sangue, como hemograma, coagulograma, prova de função renal, proteínas totais e frações, glicemia, avaliação clínica e cardiológica feita pelo especialista, cuidados per e pós-operatórios.

\section{Marcação}

Os pacientes receberam anestesia regional e antissepsia, sendo utilizados PVPI degermante, soro fisiológico e PVPI tópico. Foi demarcada com azul de metileno uma linha vertical de aproximadamente $20 \mathrm{~cm}$ de comprimento, se estendendo desde $6 \mathrm{~cm}$ do côndilo medial da tíbia, até junto ao maléolo medial (Figura 3).

Foi usada infiltração com uma solução de soro fisiológico $0,9 \%(250 \mathrm{ml})$ e uma ampola de adrenalina para vasoconstrição e minimizar o sangramento.

\section{Técnica Cirúrgica}

Após a infiltração, foi efetuada incisão de um ponto localizado entre o maléolo medial e o tendão de Aquiles, até a altura suficiente para rodar e cobrir a lesão, geralmente 


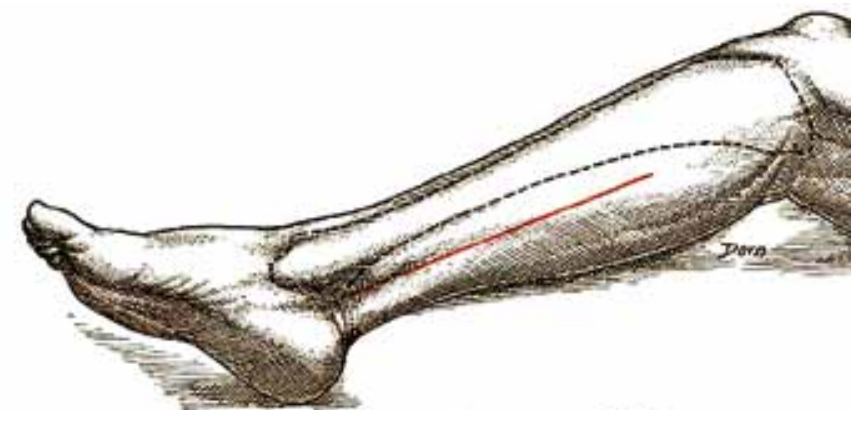

Figura 3 - Marcação da pele.

localizada na região médio posterior da perna, pouco acima do sulco formado pelo gastrocnêmio e a tíbia.

Membro inferior em posição de supinação, e rotação externa e joelho levemente flexionado, a dissecção do retalho iniciou-se com incisão na face medial da perna, incluindo pele, tecido subcutâneo e fáscia profunda na extensão necessária para a confecção do retalho (Figura 4).

$\mathrm{O}$ plano entre o músculo gastrocnêmio e o sóleo foi identificado, cuja dissecção foi praticamente avascular. $\mathrm{O}$ sóleo distalmente foi separado do compartimento posterior profundo, evitando-se lesar a fáscia intermuscular que protege o tibial posterior (Figura 5).

Os pedículos foram ligados para a liberação da porção distal do músculo ao nível do calcâneo e para dar maior arco de rotação para a cobertura da exposição óssea. O retalho foi passado por baixo da pele e suturado com vicryl e nylon 2.0 ou 3.0, ou dependendo da gravidade, foi rodado diretamente para a cobertura da lesão (Figuras 6 a 9).

A enxertia sobre o músculo foi realizado, se possível, no mesmo tempo cirúrgico, com enxerto de pele parcial retirado da

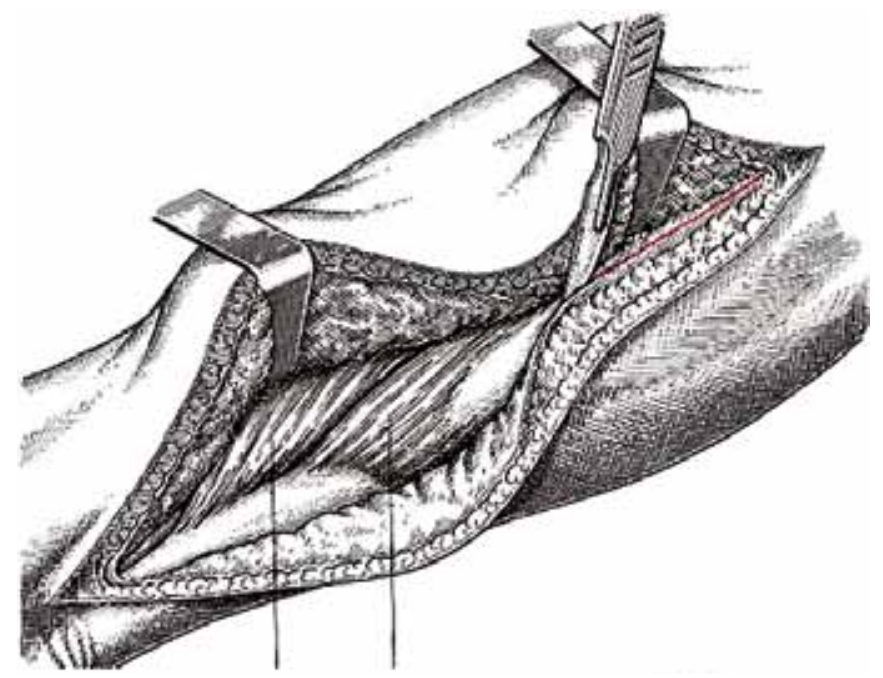

Figura 4-Incisão e descolamento.

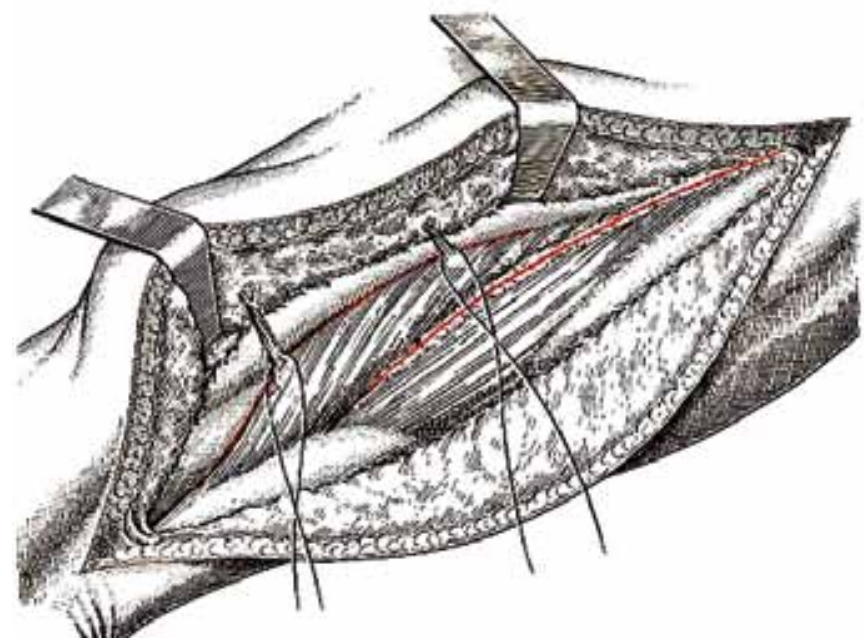

Figura 5 - Ligadura de pedículos distais.

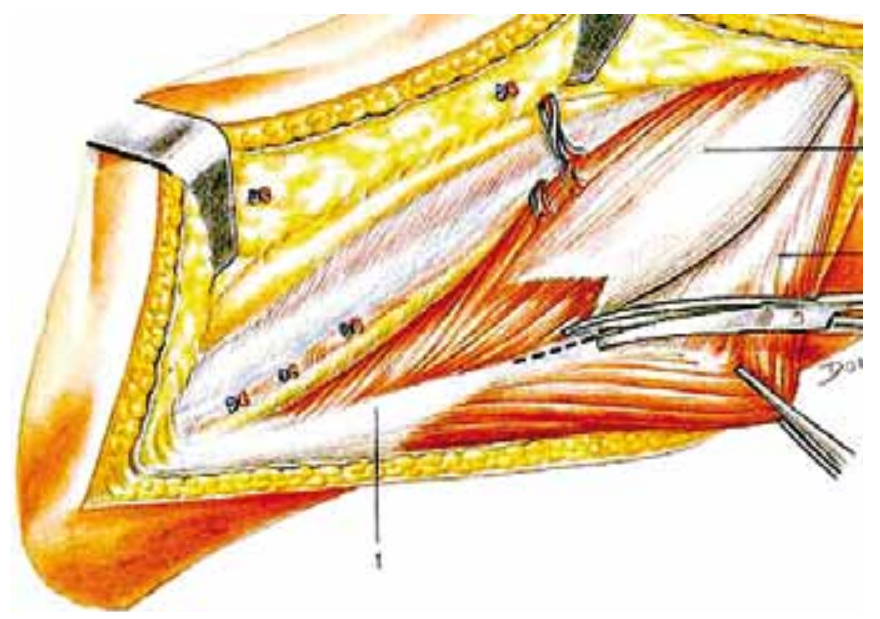

Figura 6 -Descolamento entre músculos gastrocnêmio e sóleo.

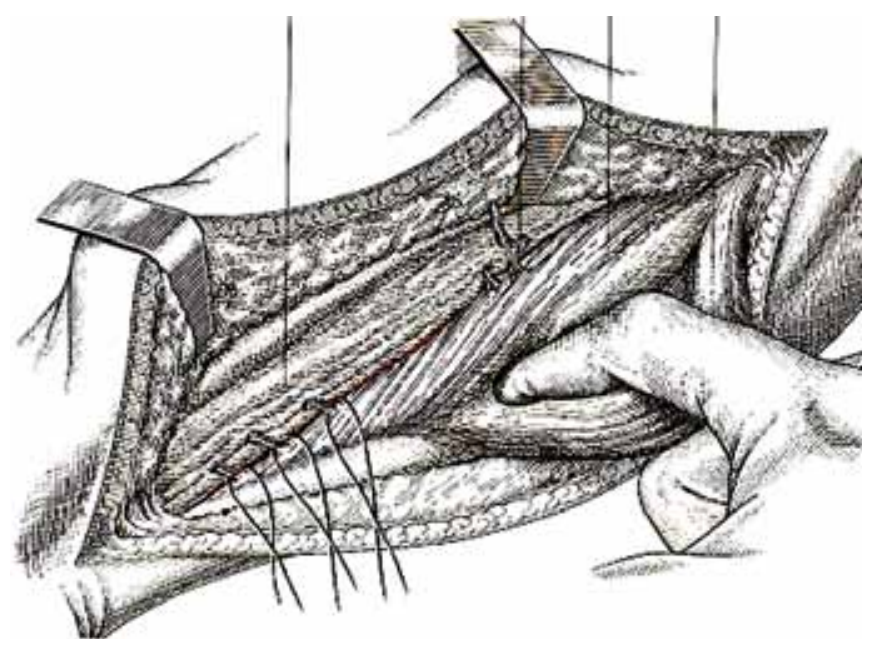

Figura 7 -Descolamento entre músculos gastrocnêmio e sóleo. 


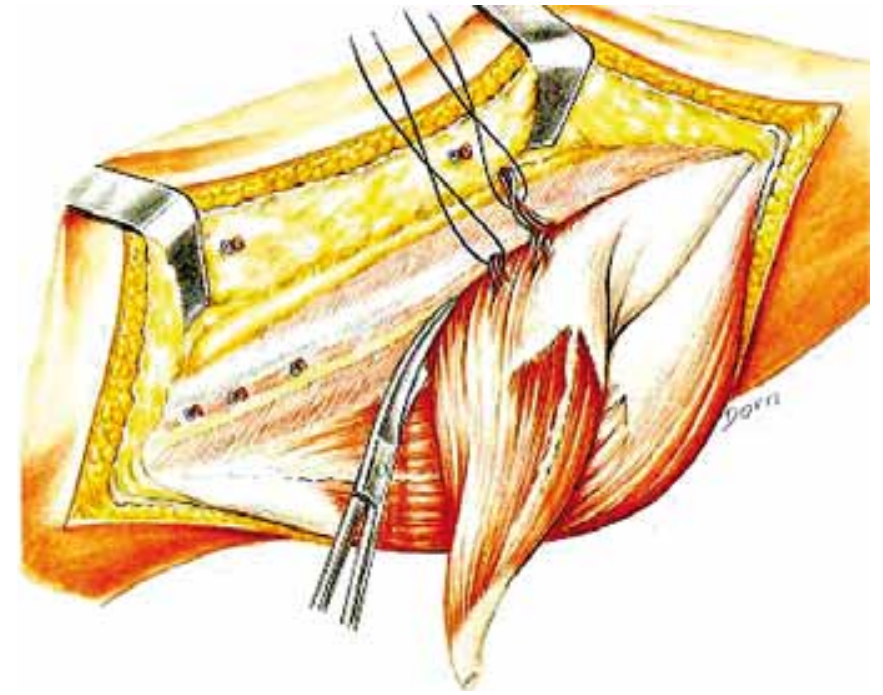

Figura 8 - Ligadura dos pediculos para rotação dos retalhos.

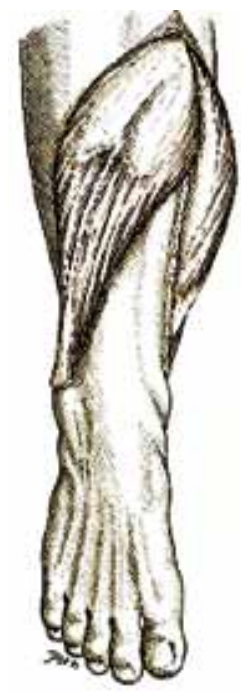

Figura 9 - Rotação do músculo sóleo, cobertura do terço médio da perna.

coxa. O leito muscular foi drenado com utilização de dreno de sucção 4.8, ou penrose (nos casos em que a área de espaço morto era pequena), e a ferida operatória suturada com nylon 2.0 ou 3.0.

Utilizou-se o retalho do músculo sóleo, sempre abordado pela face medial da perna. Em algumas ocasiões, esta incisão representou um prolongamento proximal e distal de uma das bordas da perda de substância.

\section{Pós-operatório}

O tempo decorrido entre a lesão e a rotação do retalho variou de 7 a 25 dias, nos casos em que a perda de revestimento foi consequência de trauma.
Os drenos de Penrose ou sucção foram retirados nas primeiras 48 horas e os pacientes mantidos em repouso no leito. Após 7 dias da enxertia, estes são liberados para se locomoverem com auxílio de equipamentos (cadeira de rodas, muletas, etc.). A alta hospitalar dos pacientes variou entre 7 e 15 dias. Os pontos foram retirados após 10 a 15 dias, de forma alternada.

Alguns pacientes ainda estão em tratamento, pois fraturas expostas têm reconhecidamente curso lento no sentido da consolidação. Consideramos que a estabilização do esqueleto é fundamental como condição prévia à execução de retalhos musculares. A maneira de conseguir esta estabilização variou, conforme a particularidade de cada caso.

\section{Complicações}

As complicações encontradas foram pequenas áreas de necrose na borda distal do retalho em $3(16,7 \%)$ casos, o que não comprometeu a cobertura óssea; hematoma em loja doadora muscular em $2(11,1 \%)$ casos, nos quais foi realizada drenagem em bloco cirúrgico e colocação de dreno de sucção, seroma e perda parcial do enxerto de pele parcial em $2(11,1 \%)$ casos, os quais foram submetidos a nova enxertia após uma semana.

Nenhuma das complicações comprometeu a integração dos retalhos aos seus leitos. Os resultados tardios foram satisfatórios em todos os casos.

\section{RESULTADOS}

Todos os 18 pacientes submetidos à rotação do músculo sóleo tiveram integração total dos retalhos, sem necessidade de novo procedimento cirúrgico. A permanência hospitalar variou entre 7 e 15 dias de pós-operatório.

A cicatrização da área receptora se processou sem intercorrências, em um tempo médio de 25 dias. Após a alta hospitalar, os pacientes foram acompanhados em regime ambulatorial com equipe multidisciplinar.

O procedimento cirúrgico foi realizado entre $7^{\circ}$ e $25^{\circ}$ dia após o acidente. Na avaliação dos enxertos durante a primeira troca do curativo, houve necessidade da drenagem de pequenos hematomas e seromas em $5(27,8 \%)$ pacientes, sem a necessidade de enxertia complementar.

Nenhum dos pacientes foi operado na vigência de infecção clinicamente ativa, a maioria foi operada com alguns dias de evolução, o que por vezes não dependeu diretamente da vontade da autora. A análise dos casos, no entanto, não permite ainda concluir qual a influência que este retardo na realização do retalho teve sobre a evolução do caso em questão.

Devido à cuidadosa dissecção que temos que fazer com esta técnica, a duração média da cirurgia foi de 1 hora e 30 minutos. Todos os pacientes operados estavam em 
acompanhamento pela equipe de ortopedia, o maior número deles com fixadores externos de fraturas, que foram transferidos para outros hospitais da rede hospitalar ou receberam alta com acompanhamento ambulatorial pelas equipes de ortopedia e cirurgia plástica.

Não houve nenhum caso de infecção, necrose de retalhos dermogordurosos ou deiscência de sutura que necessitasse de nova intervenção cirúrgica. Também não houve nenhum caso de complicações sistêmicas, como trombose venosa profunda, embolia pulmonar ou qualquer outra complicação.

As Figuras 10 a 25 ilustram alguns casos da presente casuística.

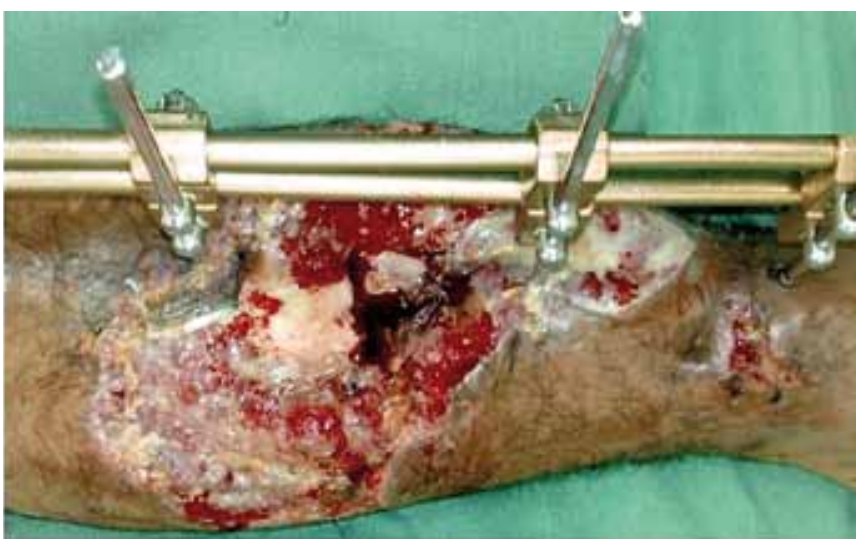

Figura 10 - Pré-operatório: exposição óssea.

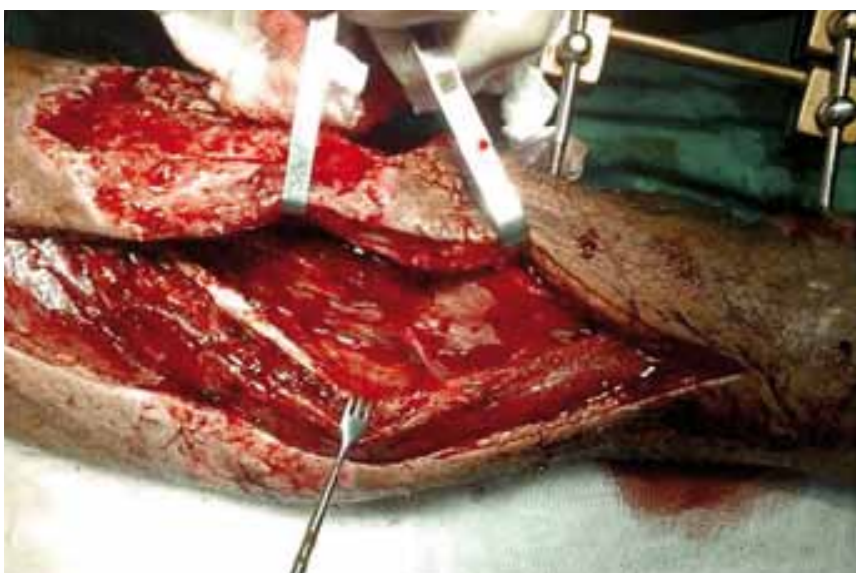

Figura 11 - Incisão, descolamento e identificação do pedículo.

\section{DISCUSSÃO}

Nas feridas extensas, aguarda-se a melhor oportunidade para debridamento em caso de necrose tecidual, o paciente permanece com curativos diários, realizando a cirurgia definitiva somente quando apresentar condições clínicas e locais apropriadas.

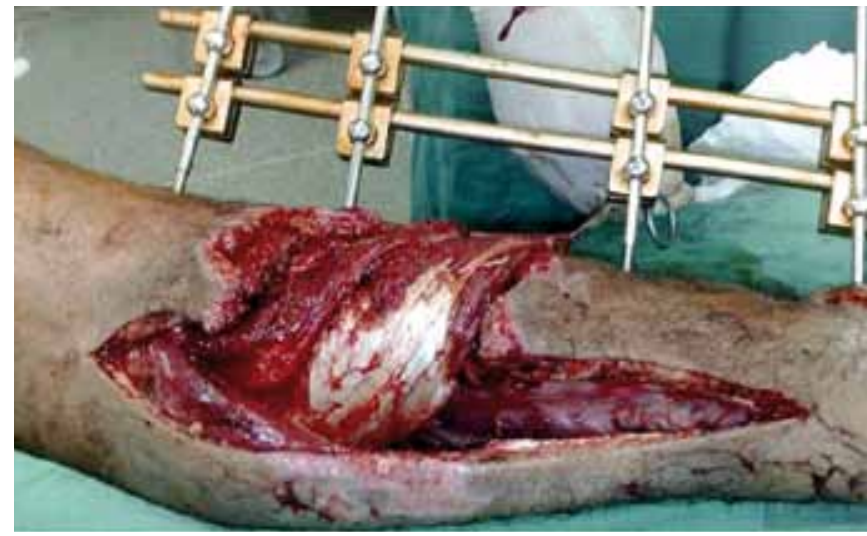

Figura 12 - Rotação do músculo sóleo e cobertura do terço médio da perna.

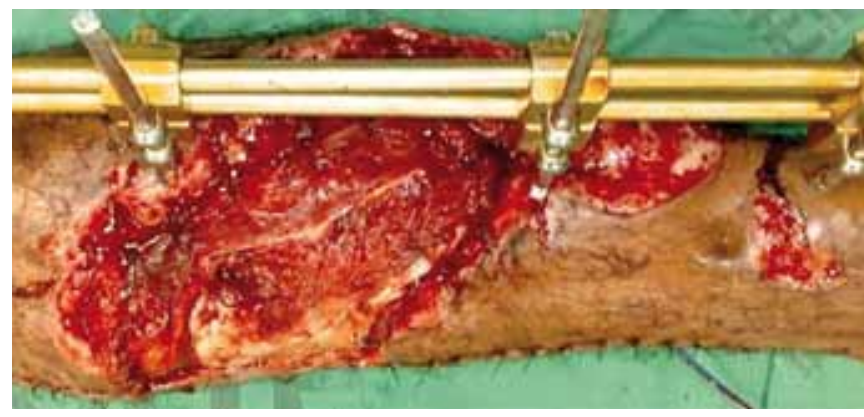

Figura 13 - Sutura do músculo junto à borda da lesão e síntese da pele.

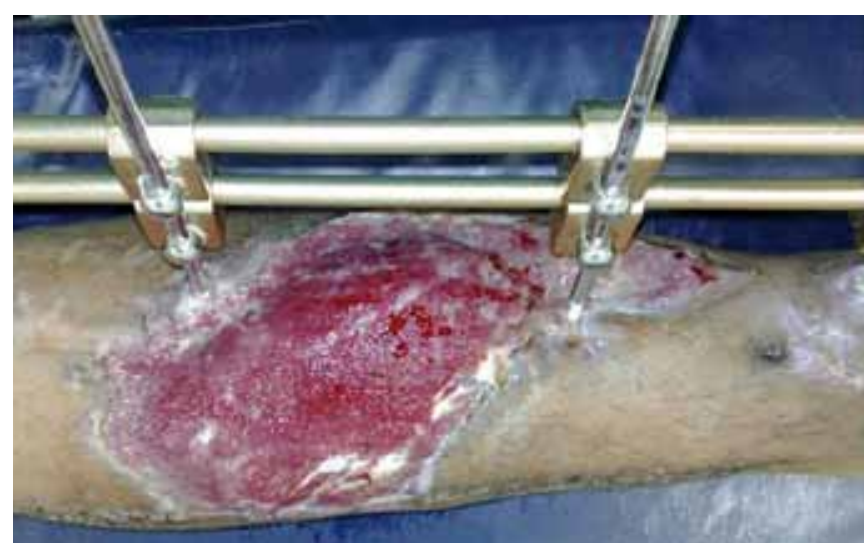

Figura 14 - Granulação muscular após 7 dias.

A literatura não é pródiga no relato de transposições múltiplas ou parciais de retalhos musculares. Contudo, quando necessário, procede-se, de rotina, ao uso de dois ou mais músculos, migrando-os parcialmente, procurando preservar a função do membro inferior, deixando a inserção tendinosa distal intacta, evitando-se sequelas funcionais 


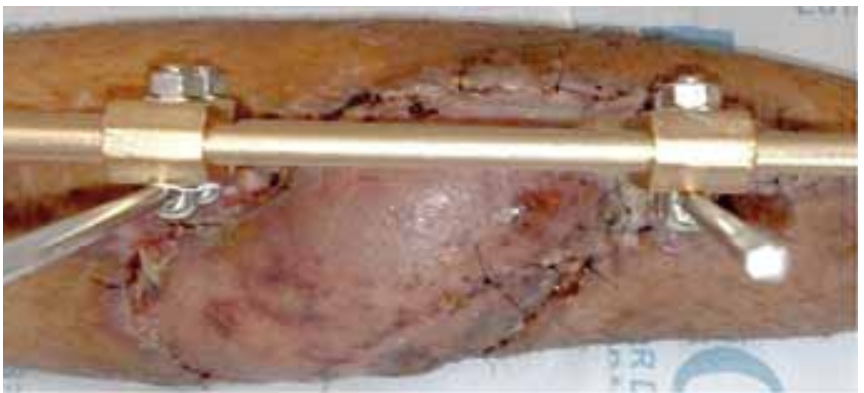

Figura 15 - Enxertia dermoepidérmica após 7 dias.

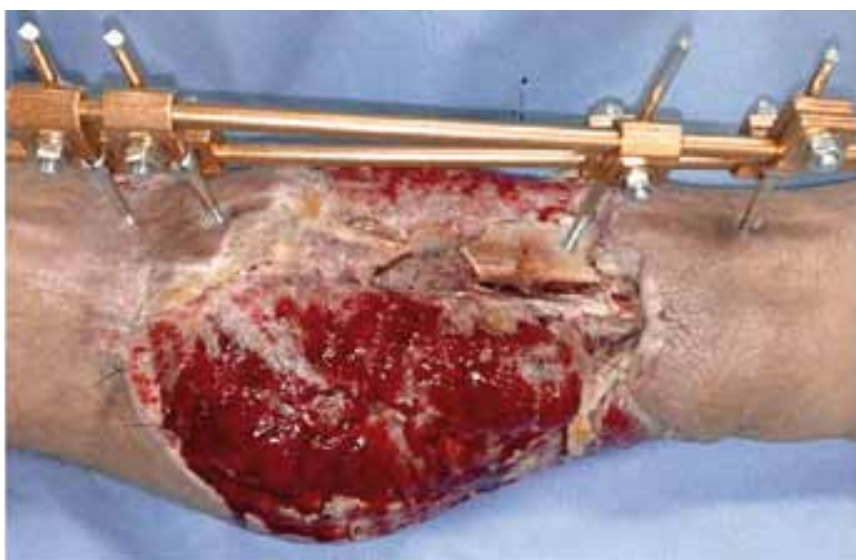

Figura 16 - Pré-operatório: exposição óssea.

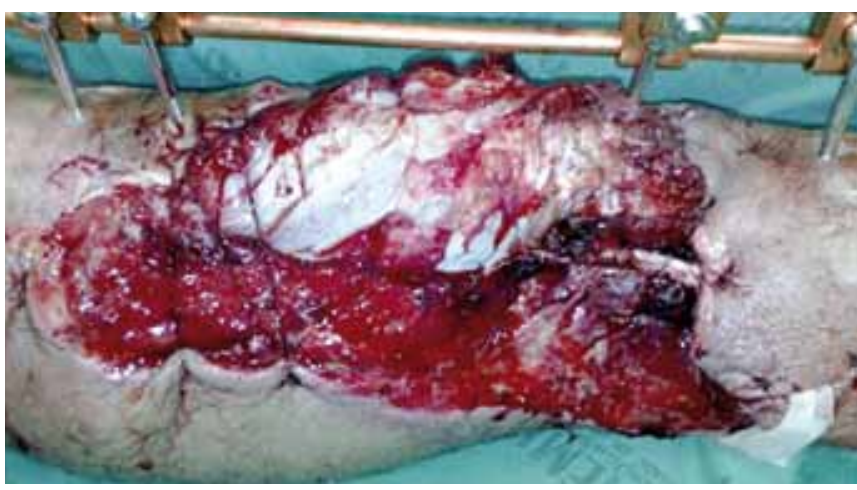

Figura 17 - Rotação do músculo sóleo e cobertura da exposição óssea.

irreversíveis, como quando são usados retalhos musculares múltiplos totais ${ }^{33-35}$.

Porém, vem crescendo na última década o uso dos retalhos musculares ou subcutâneos para o tratamento de áreas cruentas em membros inferiores ${ }^{12,36,37,38}$. Por parte dos autores citados, há unanimidade sobre as vantagens desses retalhos. O retalho do músculo sóleo também apresenta todas estas

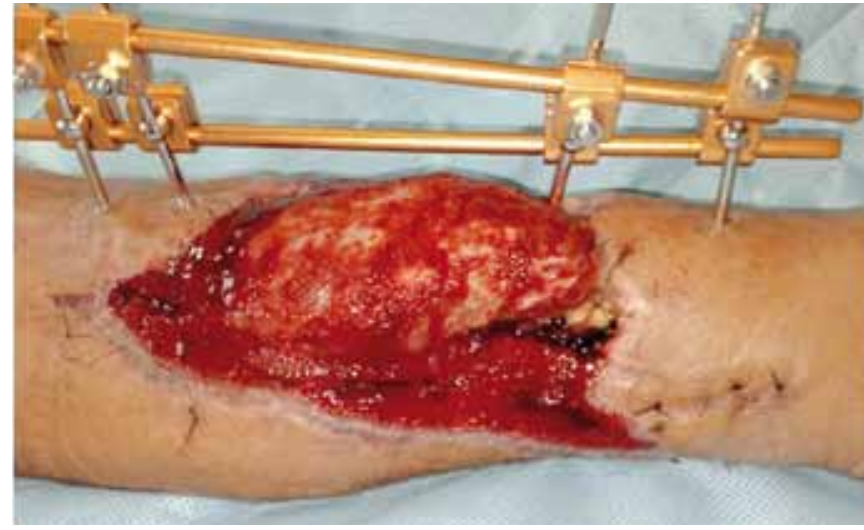

Figura 18 - Granulação da ferida após 7 dias.

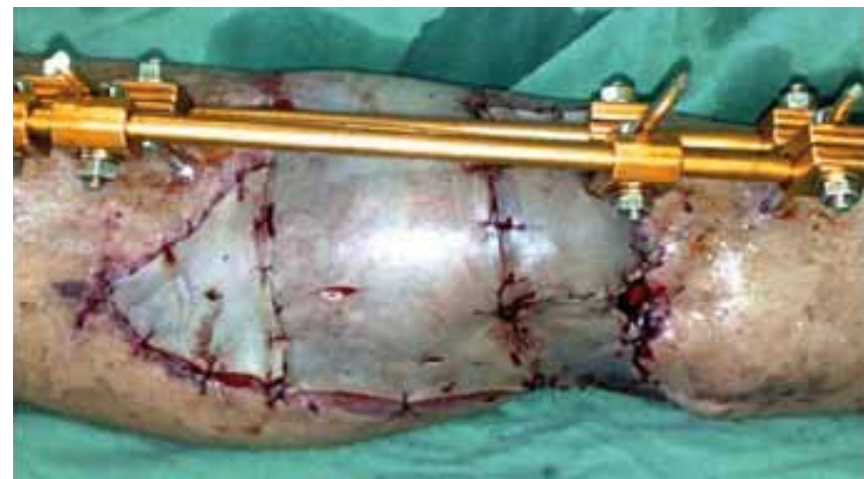

Figura 19 - Enxertia de pele parcial.

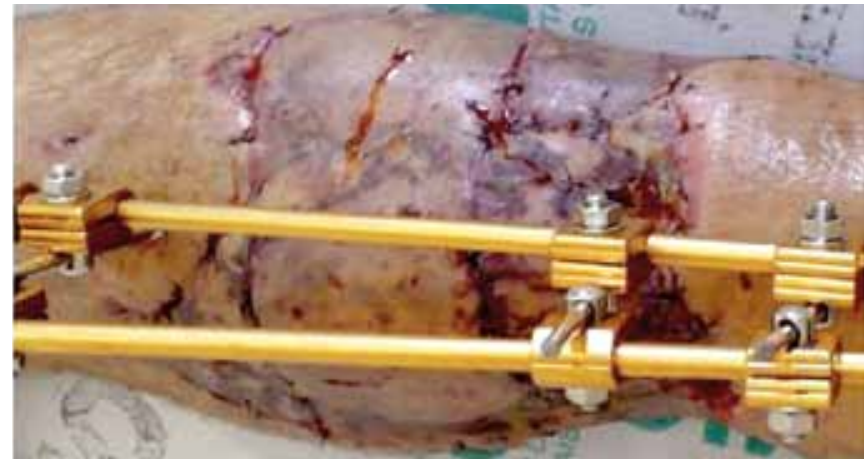

Figura 20 - Enxertia integrada após 7 dias

vantagens e constitui excelente recurso na reconstrução dos defeitos do terço médio da perna.

As vantagens são: ser flexíveis, adaptando-se a todas as superfícies, tem vascularização de padrão axial, mantendo seu volume no pós-operatório tardio, são de simples execução, podem ser enxertados em suas faces profunda ou superficial, imediata ou secundariamente, preservam os pedículos vasculares maiores e evitam defeitos antiestéticos nas áreas doadoras ${ }^{12,37,39}$. 


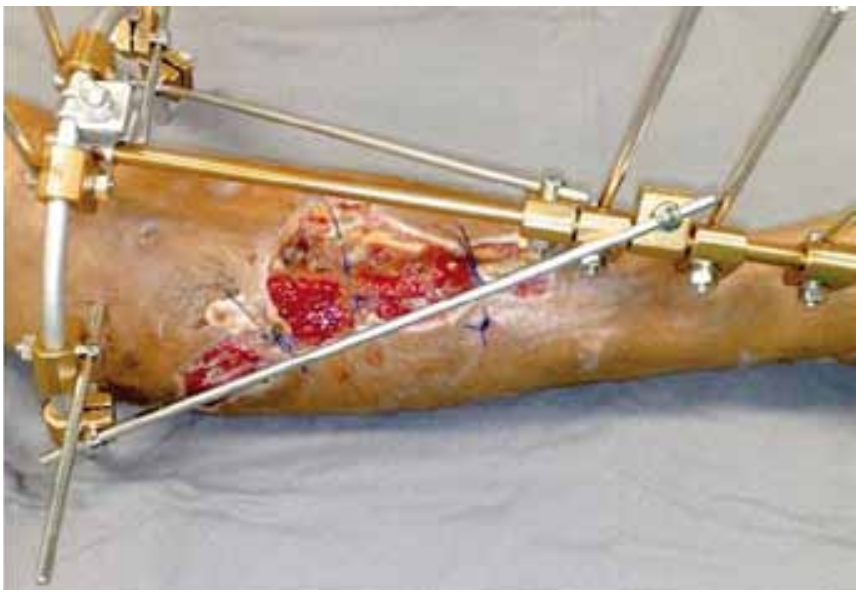

Figura 21 - Pré-operatório: exposição óssea.

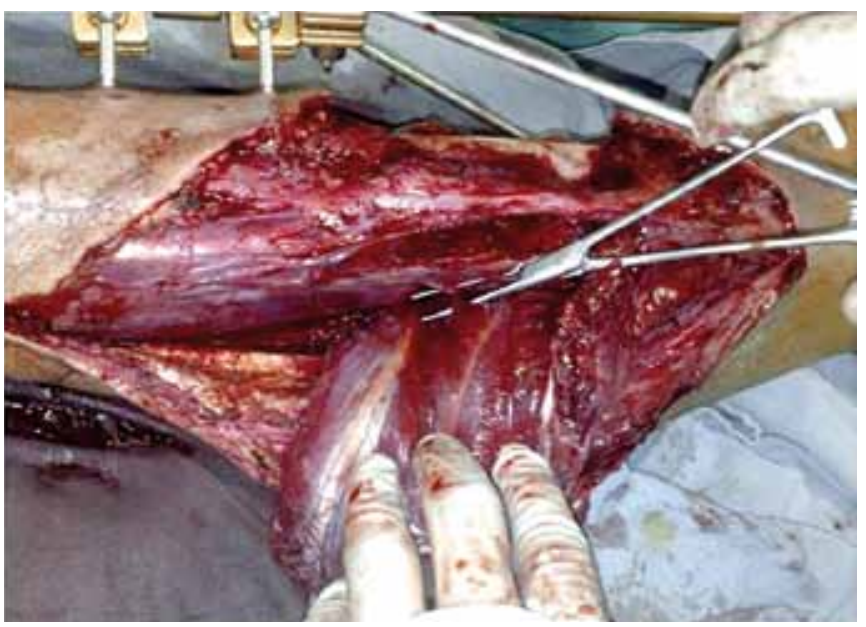

Figura 22 - Incisão, descolamento e ligadura dos pedículos.

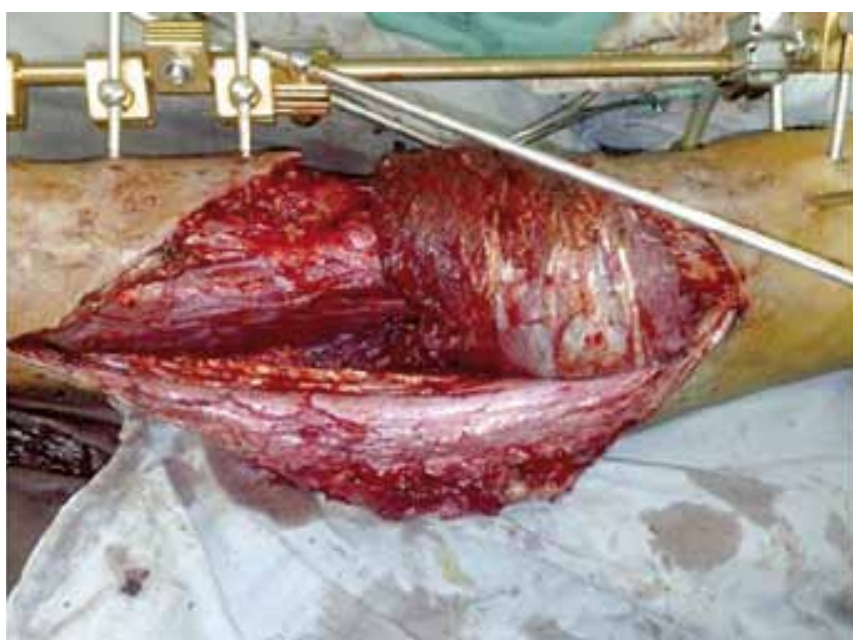

Figura 23 - Rotação do músculo sóleo e cobertura do terço médio da perna.

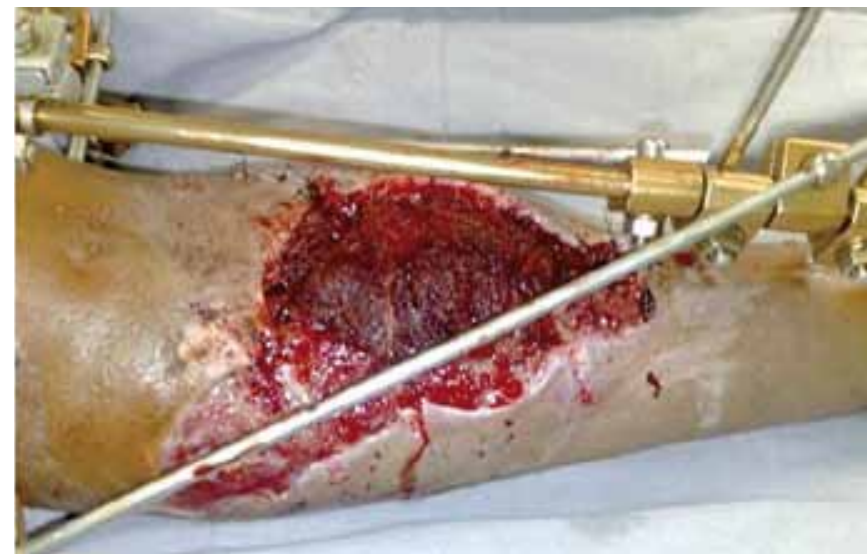

Figura 24 - Sutura do músculo junto à borda da lesão e síntese da pele.

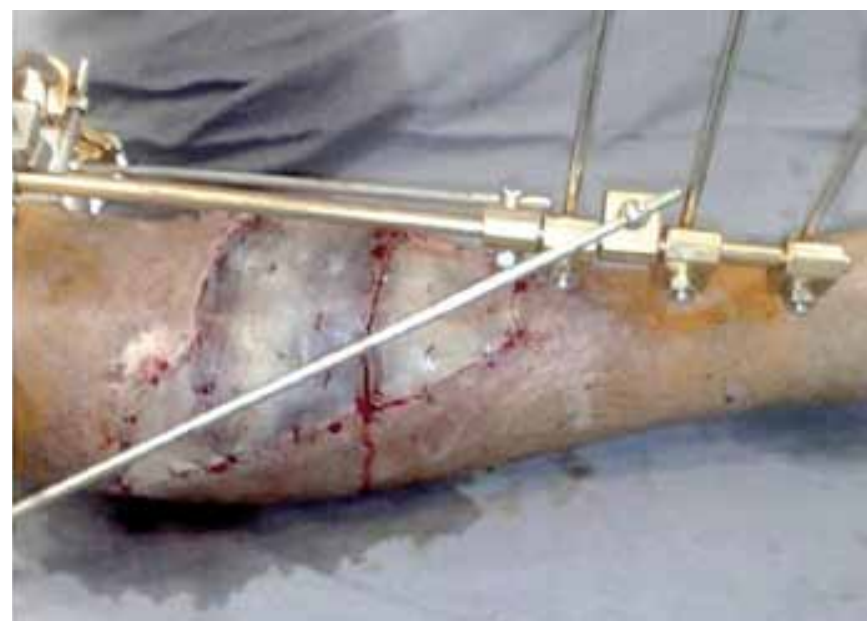

Figura 25 - Enxertia de pele parcial.

Os retalhos musculares são geralmente utilizados como parte de um planejamento cirúrgico, cujo resultado final só deve ser avaliado em função da condição patológica básica que motivou a indicação de tais retalhos.

Assim, Gerr ${ }^{40}$, em 1977, usou para preencher cavidades osteomielíticas os retalhos musculares e Byrd et aI. ${ }^{41}$, para cobrir exposições consequentes a fraturas expostas na fase aguda. Em 1982, Andrews et aI. ${ }^{27}$ empregaram como cobertura das perdas de substâncias pré-tibiais causadas por condições várias o retalho do músculo sóleo.

Os retalhos musculares devem ser executados prematuramente no tratamento de fraturas expostas da tíbia, sempre que a localização da ferida e as condições de gravidade o exijam e sempre que as condições gerais e locais o permitam.

O músculo sóleo é um importante retalho que pode ser usado para a reconstrução de perda de substância do terço medial da perna. É um retalho bastante versátil, com grande 
arco de rotação, variando de $90^{\circ}-180^{\circ 22}$, adequado para reparações de perdas de substância ao nível do terço médio e inferior de membros inferiores.

Autilização desta técnica em portadores de lesões decorrentes de diferentes etiologias vêm sendo verificada em um número pequeno de casos e sua indicação ainda continua sendo pesquisada por diversos autores, em virtude de pouca experiência individual relacionada ao problema ${ }^{9,25,26,42}$. Os autores reconhecem que o retalho favorece aumento da circulação, propicia a osteogênese, contribuindo no combate à infecção $0^{14,27-30}$.

\section{CONCLUSÃO}

Com o estudo da anatomia funcional dos músculos do membro inferior foi possível utilizar o retalho do músculo sóleo na reparação das perdas de substância em lesões do terço médio da perna.

Todavia, é imprescindível ter conhecimento da anatomia funcional, da unidade musculoesquelética, da inervação e irrigação arterial venosa dos membros inferiores para rotação do músculo.

A aplicação desse retalho tem demonstrado ser eficaz na prática, sendo mais um recurso de grande valor na solução das sequelas de traumas, nas quais outra única opção possível seria a microcirurgia com retalho livre (free flap), mas que nem sempre as condições vasculares locais permitem.

Os retalhos musculares ocasionam menores deformidades na região posterior da perna e causam um fluxo sanguíneo regional mais intenso que os retalhos cutâneos convencionais, auxiliando a consolidação das fraturas expostas e a recuperação de focos de osteomielite, devido a maiores níveis séricos locais de antibióticos e quimioterápicos e a trocas metabólicas mais eficazes.

A utilização do retalho solear de rotação para lesões do terço médio da perna é um procedimento cirúrgico de fácil execução, com resultados satisfatórios, bom resultado estético, boa cobertura, prevenindo lesões vasculares cirúrgicas, evitando sequelas funcionais irreversíveis.

Tendo em vista que o músculo sóleo encontra-se abaixo (anterior) do músculo gastrocnêmio, os resultados estéticos são aceitáveis, considerando-se a gravidade das lesões iniciais $^{19}$

Apesar de ser retalho extenso, envolvendo toda a parte posterior da perna, não deixa sequelas significativas na área doadora, além de cicatriz pouco evidente e bem posicionada. O resultado conserva-se estável com o tempo, mantendo o retalho, a textura e a espessura iniciais.

A realização da rotação de um retalho muscular não exige instrumentos ou cuidados pós-operatórios excepcionais. Pacientes submetidos a essas cirurgias vão necessitar de menor tempo de hospitalização, porém a utilização dessa técnica exige conhecimento anatômico e técnico precisos.
As técnicas de retalhos musculares, usadas também na osteomielite, envolvem a realização de enxerto de pele sobre o músculo rodado, favorecendo cobertura cutânea na face anterior da perna.

A cobertura destas áreas infectadas oferece grandes vantagens, já que o retalho é ricamente vascularizado, concedendo melhor nutrição óssea onde os elementos importantes do sangue e antibióticos podem atuar de maneira mais eficaz no combate à infecção.

O retalho do sóleo proporciona a cura do processo infeccioso desde que o procedimento ortopédico seja satisfatoriamente amplo, removendo o máximo de tecido ósseo comprometido.

O pedículo principal é proximal e é dado por ramos da artéria tibial posterior e ramos da artéria fibular. $\mathrm{O}$ ponto de rotação do retalho fica cerca de 10 a $12 \mathrm{~cm}$ abaixo do joelho, e o arco de rotação pode ser executado lateral ou medialmente ${ }^{20}$. Quando o músculo sóleo é usado, raramente ocorre déficit funcional, desde que o músculo gastrocnêmio seja resguardado.

O uso de drenos por pelo menos 48 horas é importante no pós-operatório, devido a um discreto e constante sangramento dos músculos dissecados. A funcionalidade de caminhada, deambulação, dança, salto e corrida, não são alteradas, devida à função do tríceps sural continuar normal.

Foi possível demonstrar neste trabalho que o tratamento da exposição traumática da tíbia exige, além dos métodos ortopédicos tradicionais, representados por limpeza cirúrgica adequada e antibioticoterapia, a associação do retalho muscular do sóleo, para proporcionar cobertura óssea eficiente e vantajosa.

Conclui-se que o retalho muscular do sóleo representa boa opção para cobertura de perda de revestimento cutâneo da face ântero-medial do terço médio da perna, devendo estar sempre presente no arsenal terapêutico dos cirurgiões comprometidos com esta séria e frequente contingência ortopédica.

\section{REFERÊNCIAS}

1. Cardoso M. Aplicação clínica dos retalhos musculares e músculocutâneos nas reparações da perna e pé. Rev Bras Centro Estudos Dr. Wladimir do Amaral Bol. 1982;(1):21-8.

2. Hochberg J, Bozola AR, Ramos JEA, Oliveira MC, Miura O, Vieira RC. Manual de retalhos miocutâneos. Porto Alegre:AMRIGS;1984.

3. Chapman MW. Fraturas expostas. In: Rockwood Jr CA, Green DP, Bucholz RW, Eds. Fraturas em adultos. v.1. São Paulo:Manole;1993. p.221-62.

4. Schwartsmann CR. Fraturas expostas. In: Herbert S, Xavier R, eds. Ortopedia e traumatologia: princípios e prática. Porto Alegre:Artes Médicas;1995. p.570-3.

5. Fitzgerald Jr RH, Ruttle PE, Arnold PG, Kelly PJ, Irons GB. Local muscle flaps in the treatment of chronic osteomyelitis. J Bone Joint Surg Am. 1985;67(2):175-85.

6. GerR. The technique of muscle transposition in the operative treatment of traumatic and ulcerative lesions of the leg. J Trauma. 1971;11(6):502-10. 
7. Mathes SJ, Alpert BS, Chang N. Use of the muscle fIap in chronic osteomyelitis: experimental and clinical correlation. Plast Reconstr Surg. 1982;69(5):815-29.

8. Touam C, Rostoucher P, Bhatia A, Oberlin C. Comparative study of two series of distally based fasciocutaneous flaps for coverage of the lower one-fourth of the leg, the ankle, and the foot. Plast Reconstr Surg. 2001;107(2):383-92.

9. McCraw JB, Dibbell DG, Carraway JH. Clinical definition of independent myocutaneous vascular territories. Plast Reconstr Surg. 1977;60(3):341-52.

10. Guofeng Y, Baoqui C, Yuzhi G. Forearm free skin flap transplantation. Nat Med J China. 1981;61:139. Abstract in Plast Reconstr Surg. 1982;69:1041.

11. Cormack GC, Lamberty BG. Fasciocutaneous vessels. Their distribution on the trunk and limbs, and their clinical application in tissue transfer. Anat Clin. 1984;6(2):121-31.

12. Gumener R, Zbrodowski A, Montandon D. The reversed fasciosubcutaneous flap in the leg. Plast Reconstr Surg. 1991;88(6):1034-41.

13. Pernkopf E. Miembros inferiores. In: Anatomía topográfica humana. Texto y Atlas para la disección por regiones y planos. v.2. Barcelona:Labor;1955. p.112-44.

14. Ramos RR, Bloch RJ. Reparações do membro inferior. In: Bloch RJ, Andrews JM, Chem RC, Azevedo JF, Psillakis JM, Santos ID, eds. Atlas anatomoclínico dos retalhos musculares e miocutâneos. São Paulo:Roca; 1984. p.311-68.

15. Bloch RJ, Andrews J, Chem R, Azevedo J, Psillakis JM. Atlas anatomoclínico dos retalhos musculares e miocutâneos. $1^{\mathrm{a}}$ ed. São Paulo:Roca; 1984.

16. McCraw JB, Arnold PG. Atlas of muscle and musculocutaneous flaps. Norfolk:Hampton Press; 1987.

17. Briggs JG Jr, Huang TT, Lewis SR. Use of muscle flaps in the treatment of osteomyelitis of the tibia. Tex Med. 1978;74(5):82-7.

18. Sobotta FIGGE. Atlas of human anatomy. v.3. $9^{\text {th }}$ ed. New York:Hafnes Press; 1974

19. Macedo Filho A, Lavedonio JC, Castro M, Cardoso MG. Tratamento cirúrgico para úlceras pré-tibiais utilizando retalho de músculo sóleo com fluxo invertido. An Paul Med Cir. 1995;122(1):5-10.

20. Mathes SJ, Nahai F. Clinical applications for muscle and musculocutaneous flaps. Saint Louis:Mosby; 1982.

21. Tobin GR. Hemisoleus and reseversed hemisoleus flaps. Plastic Reconstr Surg. 1985;76(1):87-96.

22. Ruttle PE, Kelly PJ, Arnold PG, Irons GB, Fitzgerald RH Jr. Chronic osteomyelitis treated with a muscle flap. Orthop Clin North Am. 1984;15(3):451-9.

23. Hochberg J. Retalhos musculares e miocutâneos. In: Mélega JM, Zanini SA, Psillakis JM, eds. Cirurgia plástica reparadora e estética. $2^{\mathrm{a}}$ ed. São Paulo:Medsi;1992. p.97-101.
24. McCraw JB, Fishman JH, Sharzer LA. The versatile gastrocnemius myocutaneous flap. Plast Reconstr Surg. 1978;62(1):15-23.

25. Feldman JJ, Cohen BE, May JW Jr. The medial gastrocnemius myocutaneous flap. Plast Reconstr Surg. 1978;61(4):531-9.

26. Morain WD. Soft-tissue reconstruction of the below-knee defects. Am J Surg. 1980;139(4):495-502.

27. Andrews JM, Ramos RR, Laredo Filho J, Lazzareschi M, Kobuti LM. Retalhos miocutâneos do músculo sóleo/gastrocnêmio em perdas de substância da perna. Rev Bras Ortop. 1982;17:20-4.

28. Jackson IT, Scheker L. Muscle and myocutaneous flaps on the lower limb. Injury. 1982;13(4):324-30.

29. Leal PRA, Lopes Neto EF, Albuquerque JS. Emprego do retalho musculocutâneo do gêmeo interno em “cross-leg". Rev Bras Cir. 1983;73:317-20.

30. Ramos RR. Reparações de perdas de substância da perna e do pé como retalho musculocutâneo dos músculos gastrocnêmio e sóleo [Tese doutorado]. São Paulo:Escola Paulista de Medicina;1985.

31. Masquelet AC, Gilbert A. Atlas colorido de retalhos na reconstrução dos membros. São Paulo:Revinter; 1997.

32. Melega JM. Cirurgia Plástica Fundamentos e Arte. Rio de Janeiro:Medsi;2004.

33. Mathes SJ, Nahai F. Muscle flap transposition with function preservation: technical and clinical considerations. Plast Reconstr Surg. 1980;66(2):242-9.

34. Moller-Larsen F, Petersen NC. Longitudinal split anterior tibial muscle flap with preserved function. Plast Reconstr Surg. 1984;74(3):398-401.

35. Riegels-Nielsen P, Krag C, Medgyesi S, Pers M. The repair of soft tissue defects in the lower leg. A comparison of different flaps techniques. Acta Othop Scand. 1983;54(5):772-6.

36. Gumener R, Montandon D, Marty F, Zbrodowski A. Subcutaneous tissue flaps in the limbs: an anatomical and clinical approach. Ann Plast Surg. 1986;16(5):377-85.

37. Lai CS, Lin SD, Yang CC, Chou CK. Adipofascial turn-over flap for reconstruction of the dorsum of the foot. Br J Plast Surg. 1991;44(3):170-4.

38. Lin SD, Lai CS, Chou CK, Tsai CW, Tsai CC. Reconstruction of soft tissue defects of the lower leg with the distally based medial adipofascial flap. Br J Plast Surg. 1994;47(2):132-7.

39. Marty FM, Montandon D, Gumener R, Zbrodowski A. The use of subcutaneous tissue flaps in the repair of soft tissue defects of the forearm and hand: an experimental and clinical study of a new technique. Br J Plast Surg. 1984;37(1):95-102.

40. Ger R. Muscle transposition for treatment and prevention of chronic post-traumatic osteomyelitis of the tibia. J Bone Joint Surg Am. 1977;59(6):784-91.

41. Byrd HS, Cierny G $3^{\text {rd }}$, Tebbetts JB. The management of open tibial fractures with associated soft-tissue loss: external pin fixation with early flap coverage. Plast Reconstr Surg. 1981;68(1):73-82.

42. James ET, Gruss JS. Closure of osteomyelitic and traumatic defect of the leg by muscle and musculocutaneous flaps. J Trauma. 1983;23(5):411-9.
Correspondência para:
Theodoria Horstt Bacelar

Rua Santa Catarina, 613 Apto.1104 - Lourdes - Belo Horizonte, MG, Brasil - CEP 30170-080

E-mail: thbacelar@hotmail.com 